\title{
Recruit-recruit interactions, density-dependent processes and population persistence in the eastern oyster Crassostrea virginica
}

\author{
Antony M. Knights ${ }^{1, *}$, Keith Walters ${ }^{1}$ \\ ${ }^{1}$ Department of Marine Science, Coastal Carolina University, Conway, South Carolina 29528, USA
}

\begin{abstract}
The supply and successful settlement of larvae is vital for the development and persistence of populations of many marine species. Strongly influenced by hydrodynamic processes, the rate of supply affects the interaction between recruits. Population structure is determined by densityindependent mortality when recruitment is limited, and by density-dependent mortality when saturated; however, the extent to which these processes determine population structure remains unclear. The relationship between recruitment and density-dependent processes in population persistence was examined in South Carolina for the eastern oyster Crassostrea virginica. Over a range of recruit densities, the resultant change in population structure was compared at locations characterised by high or low water velocities. A regionally consistent relationship between recruit density and population size indicated both density-independent and density-dependent mortality effects. Population growth was strongly positive at low and intermediate recruitment, where recruitment rates exceeded mortality. Population growth was strongly negative at extremely low and high recruitment, where density-independent mortality exceeds survival at very low recruitment rates, and densitydependent mortality reduces population size at high recruitment rates. Flow velocity affected recruitment rates, with high flow rates enhancing short-term recruitment; however, in the long-term, populations in high and low flow regions exhibited comparable recruit densities, suggesting resource limitation. Therefore, population structure of $C$. virginica is likely determined by carrying capacity and fluctuating rates of density-dependent mortality and not by rate of supply.
\end{abstract}

KEY WORDS: Larval supply $\cdot$ Recruitment $\cdot$ Density-dependence $\cdot$ Population structure $\cdot$ Crassostrea virginica $\cdot$ Hydrodynamics $\cdot$ Carrying capacity

\section{INTRODUCTION}

Efforts to maintain species abundance and diversity are ongoing as extinction rates continue to climb (Regan et al. 2001). The majority of studies have focused on the extinction of higher trophic levels, primarily as most human-induced extinctions target those species (e.g. Pimm et al. 1988, Byrnes et al. 2007). Habitat-forming, intermediate trophic level species are often overlooked with the loss of a single population having potentially dramatic consequences for the persistence of local and regional populations (Coen et al. 1999). Appreciable resources to restore and supple- ment populations of key species have been expended by many restoration projects; however, identification of the processes that influence the successful development of those populations is often not the priority. The relationship between restoration goals and the chosen metrics are often complicated by variable approaches to data collection and analysis (Walters \& Coen 2006) which rely on correlative approaches to identify patterns rather than determining the mechanism that underlies them. For example, site and population selection is typically based on convenience rather than on selection which considers favourable physical or biological characteristics. As a result, population suc- 
cess or failure cannot be attributed to a specific mechanism. Understanding the mechanisms that drive the structure and development of populations is therefore a fundamental goal that remains to be pursued.

In open marine systems, connectivity among populations reduces the risk of population extinction (den Boer 1981), strongly influencing population dynamics and evolution (McQuaid \& Phillips 2000, Kritzer \& Sale 2004). Many marine species exhibit a complex life cycle which often includes a dispersive planktonic stage prior to metamorphosis into a bottom-dwelling phase (Thorson 1950). Hydrodynamic processes are important for transport, with larvae utilising currents to disperse over potentially great distances, thus regulating the supply of larvae to potential settlement sites (Armonies \& Hellwigarmonies 1992, Leonard et al. 1998). Pelagic larvae have a limited swimming ability (e.g. $0.25 \mathrm{~cm} \mathrm{~s}^{-1}$ for Crassostrea virginica, Mann \& Rainer 1990), and in the absence of detailed knowledge of behaviour, larvae are considered as passive particles, and water advection and water flux characteristics can greatly influence recruitment (Judge \& Craig 1997, Leonard et al. 1998, but see Knights et al. 2006). Turbulent mixing or bed shear associated with fast currents may resuspend dynamic substrates, reduce substrate contact and reduce settlement success (e.g. Roegner 2000, Bouma et al. 2001, Pernet et al. 2003). Consequently, recruitment within high and low flow regimes may exhibit markedly different rates of settlement and confound the interaction between larval supply, recruitment and post-settlement survivorship (Abbe 1986, Kennedy 1986, Kingsford 1993, Hanski \& Simberloff 1997, Underwood \& Keough 2001). Therefore, understanding of the role of flow in settlement success is critical in population dynamics estimates.

In order for a population to develop, new recruits must reach a habitat and arrive in sufficient numbers to dominate interspecific interactions (Underwood \& Keough 2001). The growth and persistence of those populations are likely dependent on intraspecific interactions; however, these interactions may be strongly affected by the timing and density of recruitment. For example, mortality rates may increase and growth rates decrease in conjunction with increasing recruit densities. In resource-limited environments (e.g. food and space), population growth results in fewer resources for individuals for both growth and reproduction (Gotelli 2001) and, consequently, reduced population growth (dilution or resource concentration hypothesis; see Iles \& Beverton 2000 for review). Therefore, the availability of resources and the timing and density of recruitment for a given habitat are likely drivers of density-dependent processes and are important in the development and structure of populations and population self-regulation. While considered a ubiquitous process, self-regulation in natural populations may be subject to temporal changes in both environmental conditions and recruit supply (Murdoch \& McCauley 1985). Not only are interactions likely to be density-dependent among recruits, but also between recruits and extant adults. Changes in adult density in existing populations can affect the 'attractiveness' of the habitat. Greater adult densities increase the concentration of chemical attractants (Woodin 1976, Raimondi 1988) and the probability of physical contact between conspecific recruits and previously settled adults, enhancing settlement (Crisp \& Meadows 1962, Burke 1986, Raimondi 1988) and potentially confounding settlement patterns. It is therefore critical that the role of intraspecific density-dependent processes among recruits and local hydrodynamics be assessed at local scales if predictions of population dynamics and in-depth studies of patterns and processes are to be understood at more complex regional scales (Begon et al. 1990).

Crassostrea virginica is considered a keystone species (Jones et al. 1994) on the eastern coast of the United States and provides foundation ecosystem services, such as sediment stabilisation and erosion control, hard and soft substrate creation for benthic organisms and water quality improvement (Breitburg 1999, Coen et al. 1999, Lenihan 1999, Newell 2004). The decline in natural oyster populations has led to a concerted effort to maintain and/or restore both intertidal and subtidal oyster reefs in many Atlantic and Gulf Coast states. This paper presents the results of a study to determine the effect of local and regional differences in recruitment rates on population structure in intertidal habitats with differing flow regimes. The study tested (1) whether bimonthly recruitment rates could be used to predict population structure, (2) if flow regime affects recruitment success, in addition to (3) assessing the role of density-independent, and (4) density-dependent interactions among recruits in determining the growth, development and structure of populations.

\section{MATERIALS AND METHODS}

Study system. The experiment was conducted at 3 locations in South Carolina, USA: Murrells Inlet $\left(33^{\circ} 33^{\prime} 37.78^{\prime \prime} \mathrm{N}, 79^{\circ} 01^{\prime} 05.70^{\prime \prime} \mathrm{W}\right)$, North Inlet-Winyah Bay ( $\left.33^{\circ} 20^{\prime} 50.61^{\prime \prime} \mathrm{N}, 79^{\circ} 10^{\prime} 17.94^{\prime \prime} \mathrm{W}\right)$, and Cape Romain (32 55' 40.31" N, 79 38' 15.12" W) (Fig. 1), which are separated by $10 \mathrm{~s}$ of $\mathrm{km}$. All 3 locations are estuarine and situated between the mainland and barrier islands and include salt marshes, mudflats and extensive native bivalve beds of clams Mercenaria mercenaria and oysters Crassostrea virginica. Murrells Inlet 


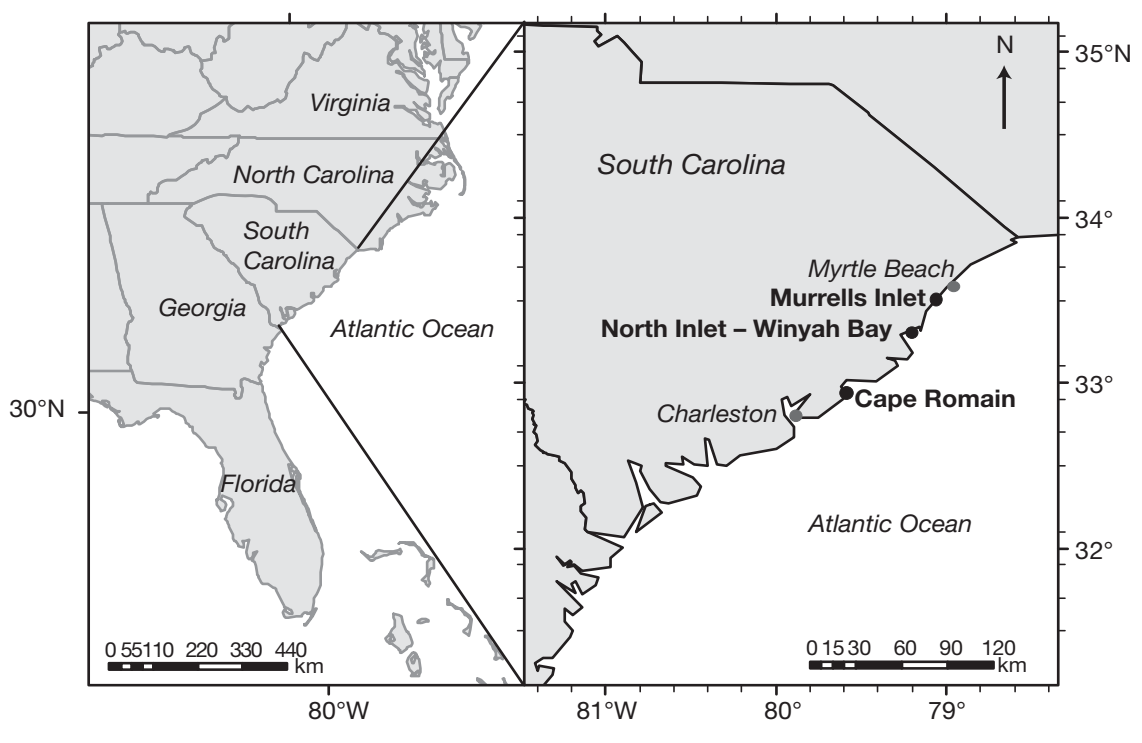

Fig. 1. Study locations (bold) on the eastern coast of the USA

an exploratory approach was taken based on a null hypothesis to examine any potential factors.

Recruitment was estimated using $9 \times 9 \mathrm{~cm}\left(0.0081 \mathrm{~m}^{2}\right)$ tiles made of unglazed red clay (Versatile) as a substrate for attachment. At the beginning of the experiment, 24 tiles were haphazardly placed throughout the oyster bed, 3 of which were biweekly treatments and 21 the cumulative treatment. Each tile was secured to a $60 \mathrm{~cm}$ pole of PVC (20 mm diameter) that was driven into the mud to secure its position within the bed. Tiles were attached by a cable tie passing through a loop of $10 \mathrm{lb}$ monofilament fishing line glued to the edge of the tile using Sumo $^{\mathrm{TM}}$ glue (Loctite). Every 2 wk for a total of $14 \mathrm{wk}, 3$ biweekly and 3 cumulative tiles were randomly collected. Biweekly tiles

is a commercially developed area, regularly visited by recreational fishers and boaters. North Inlet is a National Estuarine Research Reserve Site (NERRS) encompassing 12327 acres of tidal marsh and wetland. Cape Romain is a migratory bird refuge and a Class I wilderness national wildlife refuge covering 64000 acres. All 3 areas are accessible by boat only and are ocean-dominated, comprising both exposed and sheltered creeks. Our experiment was conducted on intertidal mudflats within and adjacent to native oyster beds.

Field methods: oyster recruitment rates. The experiment ran from May to September 2007, incorporating the peak oyster spawning and recruitment periods (Michener \& Kenny 1991). Two treatments, (1) every 2 wk (biweekly) recruitment and (2) cumulative recruitment, were established and replicated to estimate recruitment within an oyster bed at 4 sites within each location to test specific hypotheses. The biweekly treatment estimated recruitment over a 2 wk period. The cumulative treatment estimated recruitment over 7 periods of varying length, i.e. $2,4,6,8,10,12$ or $14 \mathrm{wk}$. Cumulative treatments estimated the change in population size in each period in relation to additional recruitment and provided a proxy for densitydependent effects of existing population size on subsequent recruitment. If the cumulative number of recruits on biweekly tiles (two 2 wk tiles combined) indicated recruit numbers equivalent on a $4 \mathrm{wk}$ cumulative tile from the same period, recruitment would be considered a physical (supply) process. Differing numbers on cumulative and biweekly tiles would indicate that other factors also affect recruitment. Therefore, were replaced with new tiles which were to be collected on the next visit.

Each recruitment tile was washed through a $63 \mu \mathrm{m}$ sieve and all oysters on the tile and from the sieve fraction were counted using a stereo microscope (Olympus BX10). The total number of recruits per tile was recorded. Cumulative treatment recruit densities estimated from tiles left in the field for $2,4,6,8,10,12$ and $14 \mathrm{wk}$ were compared to additive recruit densities from biweekly settlement, calculated as densities from each 2 wk biweekly tile added together to correspond to the equivalent cumulative treatment exposure, e.g. 6 wk cumulative $=($ Week $0-2)+($ Week $2-4)+($ Week 4-6) biweekly.

Effect of flow on recruitment. To test the effect of water flow rates on recruitment, 4 sites within each location were stratified as one of 2 flow types. Geomorphological differences, i.e. main tidal creeks and back bay tributaries, were initially used to arbitrarily differentiate sites as either high flow (main tidal creeks) or low flow (back bays) sites. Two high flow and 2 low flow sites were established at each location. Flow velocities at each site were not measured directly; a gypsum dissolution method (Yund et al. 1991, Thompson \& Glenn, 1994) was used as an indirect measure of flow. This low-cost approach has been shown to provide a crude measure of water velocity, whereby rates of gypsum dissolution are directly proportional to flow rate (Yund et al. 1991, Thompson \& Glenn, 1994, but see Porter et al. 2000). Six replicate clods were placed haphazardly throughout each site and dissolution rates estimated over 2D. A 1-factor ANOVA was used to compare gypsum dissolution among all 12 sites and to 
Table 1. Proportional change in gypsum dissolution $(n=6)$ at 12 sites: 6 high and 6 low flow $(2$ sites per flow type per location) in South Carolina, USA. ns: not significant

\begin{tabular}{|lcrcc|}
\hline Source of variation & df & MS & $F$ & $p$ \\
\hline Site & 11 & 97.38 & 74.91 & $0.001^{* * *}$ \\
Residual & 60 & 1.30 & & \\
Cochran's C-test & & $0.26, \mathrm{~ns}$ & & \\
\hline
\end{tabular}

assess the differentiation of low and high flow sites based on geomorphological differences. Due to small variations in initial clod mass $(0.159 \pm 0.05 \mathrm{~g})$, proportional change, rather than absolute values, was used to compare dissolution rates and showed a significant difference among sites (Table 1: $\mathrm{p}<0.001$ ). Student Newman-Keuls (SNK) post-hoc test indicated that mean gypsum dissolution rates at high flow designated sites were $25 \%$ greater $(10.09 \pm 1.21 \mathrm{~g}, 10 \%$ dissolution $)$ than at sites characterised as low flow $(2.54 \pm 0.17 \mathrm{~g}$, $2.5 \%$ dissolution) type sites. Weight loss was interpreted to be directly proportional to water flow, suggesting that flow rates at high flow sites are 4 times faster than at low flow sites. Comparison of the mean proportional dissolution among sites indicated that sites characterised as low flow sites were not significantly different (SNK tests, $\mathrm{p}=0.01$ ), and sites characterised as high flow sites were not significantly different from each other among locations (SNK tests, $\mathrm{p}=$ 0.01).

Statistical analyses. Analysis of variance (ANOVA) was used to test for differences in spatial and temporal recruitment patterns on to biweekly and cumulative treatments, and the effect of flow on oyster recruitment over time. A nested-ANOVA with the factors Location (Murrells Inlet, North Inlet, Cape Romain), Site (Location) (4 sites nested within each location), and Time (7 levels) was used to compare recruitment rates (biweekly treatment) and population size (cumulative treatment) at small (within site) and large (among locations) spatial scales over time. Site was nested within Location as recruitment differences at small spatial scales were expected, with this approach allowing partitioning of such variation to allow assessment of the main effects (i.e. Location and Time). A 2-factor orthogonal ANOVA was used to test the effects of Flow (2 levels: high vs. low) and Time (7 levels: 2, 4, 6, $8,10,12,14 \mathrm{wk}$ ) on recruitment within biweekly and cumulative treatments. WinGMAV5 was used for all ANOVA computations (Underwood \& Chapman 1998). Prior to performing ANOVAs, Cochran's C-test for homogeneity of variance was performed. Data were heterogeneous and log-transformed to remove heterogeneity, where possible (Underwood 1997). The SNK procedure was used to make post-hoc comparisons among levels of significant terms (Day \& Quinn 1989).

The change in the abundance of recruits on biweekly versus cumulative tiles was compared using the Wilcoxon rank-sum test $(W)$ (Hollander \& Wolfe 1973) for each 2 wk period and tests the null hypothesis that the number of recruits arriving onto biweekly and cumulative tiles are no different. Therefore, biweekly tiles represent a proxy to estimate the rate of recruitment in each $2 \mathrm{wk}$ period, and are compared to the total change in recruit numbers on cumulative tiles over the same period (e.g. cumulative abundance at time-1 compared to cumulative abundance at time-2). This value may be either positive or negative, with each set of replicate cumulative tiles representing an independent estimate of the number of recruits, incorporating both recruitment and post-settlement mortality. Positive growth may be indicative of factors such as conspecific attraction; population growth (i.e. number of new recruits) on cumulative tiles is at a greater rate than in biweekly treatments, suggesting 'preference' toward cumulative treatments. Alternatively, higher negative values on cumulative treatments than biweekly treatments suggest greater post-settlement mortality in relation to new recruit arrival and/or reduced recruitment rates on cumulative treatments.

The relationship between per capita mortality and recruit density provides a statistically robust approach to assess density-dependent mortality (Caley et al. 1996). Density dependence occurs when mortality increases as density increases, with the slope of the relationship indicating the strength of density dependence. A linear relationship indicates a constant per capita effect across the density gradient, whereas a polynomial relationship indicates variable rates of density-dependent mortality across the gradient. Values may indicate either increasing (negative slope) or decreasing (positive slope) density-dependent mortality with density.

Density-dependent mortality was evaluated using regression analysis and data compared by the fit of a linear regression model over a polynomial model. Both linear and polynomial regression models were tested for significance using ANOVA (Sokal \& Rohlf 1995). Polynomial models up to the 3rd power were compared for best fit. F-test probabilities indicate the model of best fit.

\section{RESULTS}

\section{Temporal patterns of biweekly recruitment}

Of the 504 tiles monitored, Crassostrea virginica recruits were found on all tiles during all sampling 
Table 2. Crassostrea virginica. Temporal recruitment patterns of oyster larvae at 4 sites in each of 3 locations per 2 wk period for 14 wk. Data are $\ln (x+1)$ transformed. $F$ versus indicates which (source of variation) MS denominator was used for each $F$-test, e.g. $F_{\text {Location }}=\mathrm{MS}_{\text {Location }} / \mathrm{MS}_{\text {Site(Location) }}{ }^{*} \mathrm{p}<0.05,{ }^{* *} \mathrm{p}<0.01,{ }^{* * *} \mathrm{p}<0.001, \mathrm{~ns}=$ not significant

\begin{tabular}{|c|c|c|c|c|c|c|c|c|}
\hline \multirow[t]{2}{*}{ Source of variation } & \multirow[t]{2}{*}{ df } & \multicolumn{3}{|c|}{ Biweekly } & \multicolumn{3}{|c|}{ Cumulative } & \multirow[t]{2}{*}{$F$ versus } \\
\hline & & MS & $F$ & $\mathrm{p}$ & MS & $F$ & $\mathrm{p}$ & \\
\hline (a) Location & 2 & 5.05 & 1.18 & 0.349 & 61.07 & 9.00 & $0.007^{* *}$ & (b) \\
\hline (b) Site (Location) & 9 & 4.26 & 4.74 & $0.000^{* * *}$ & 6.78 & 6.40 & $0.000^{* * *}$ & (f) \\
\hline (c) Time & 6 & 28.93 & 20.93 & $0.000^{* * *}$ & 5.22 & 2.53 & $0.031^{*}$ & (e) \\
\hline (d) Location $\times$ Time & 12 & 9.75 & 7.06 & $0.000^{* * *}$ & 3.12 & 1.51 & 0.148 & (e) \\
\hline (e) Time $\times$ Site (Location) & 54 & 1.38 & 1.54 & $0.021^{*}$ & 2.06 & 1.94 & $0.001^{* * *}$ & (f) \\
\hline (f) Residual & 168 & 4.09 & & & 1.06 & & & \\
\hline Cochran's $C$-test & & $0.04, \mathrm{~ns}$ & & & $0.04, \mathrm{~ns}$ & & & \\
\hline
\end{tabular}

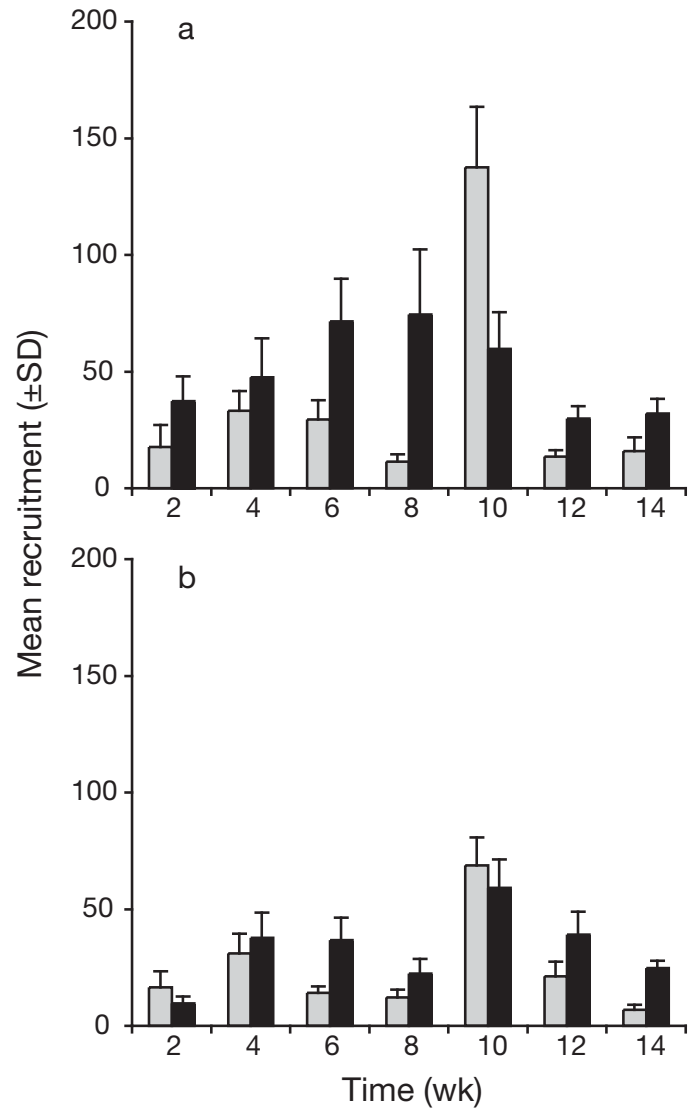

Fig. 2. Crassostrea virginica. Temporal patterns of oyster larvae recruitment on biweekly (grey bars) and cumulative (black bars) tiles in (a) high and (b) low flow regimes in South Carolina, USA

periods. The number of recruits varied among sites within locations, but in general there was little variation between locations (Table 2: Location $\times$ Time, SNK tests). Two recruitment peaks were apparent: first, a smaller peak in early June (Week 2-4) followed by a second peak in early to mid-July (4th July to 18th July) Week 8-10 (Fig. 2). On average, between 17 and 13\%
Table 3. Crassostrea virginica. Temporal recruitment patterns of oyster larvae in relation to flow and time. Data are pooled across locations (see Table 1$)$ and are $\ln (x+1)$ transformed. ${ }^{*} \mathrm{p}<0.05,{ }^{* *} \mathrm{p}<0.01, \mathrm{~ns}=$ not significant

\begin{tabular}{|lrrrrrrrr|}
\hline \multirow{2}{*}{$\begin{array}{l}\text { Source of } \\
\text { variation }\end{array}$} & df & \multicolumn{3}{c}{ Biweekly } & \multicolumn{4}{c|}{ Cumulative } \\
& & MS & \multicolumn{1}{c|}{$F$} & p & MS & $F$ & $p$ \\
\hline Flow & 1 & 4.38 & 2.71 & 0.101 & 8.31 & 4.07 & $0.045^{*}$ \\
Time & 6 & 28.93 & 17.93 & $0.000^{* *}$ & 5.22 & 2.56 & $0.020^{*}$ \\
Flow $\times$ Time & 6 & 0.49 & 0.31 & 0.932 & 2.61 & 1.28 & 0.267 \\
Residual & 238 & 1.61 & & 2.04 & & & \\
Cochran's & & 0.13, ns & & & $0.10, \mathrm{~ns}$ \\
$\quad$-test & & & & & & & \\
& & & & & & & \\
\hline
\end{tabular}

(early June), and 40 and $53 \%$ (early to mid-July) of the total recruit densities settled onto biweekly tiles during this period in low and high flow locations, respectively (Fig. 2). Flow type had no significant effect on the number of recruits at any given time (Table 3).

\section{Change in cumulative recruit density}

Recruitment onto cumulative tiles varied between sites within location, but was similar among locations (Table 2). Oyster densities were significantly higher at high flow than at low flow sites with average abundances of $44 \pm 4$ and $29 \pm 2$ oysters, respectively (Table 3).

Two general patterns were apparent. In high flow, cumulative recruit densities initially increased in conjunction with recruitment onto biweekly tiles. Cumulative recruitment densities were greatest between Week 6 and 8 (75 \pm 28 per tile), after which recruit densities decreased for each subsequent 2 wk period (Fig. 2, Table 3). Of the 18 tiles monitored at each location, oyster densities were not significantly different after $14 \mathrm{wk}$, when on average, $32 \pm 6$ remained (Fig. 2, Table 3, Time, SNK tests). 

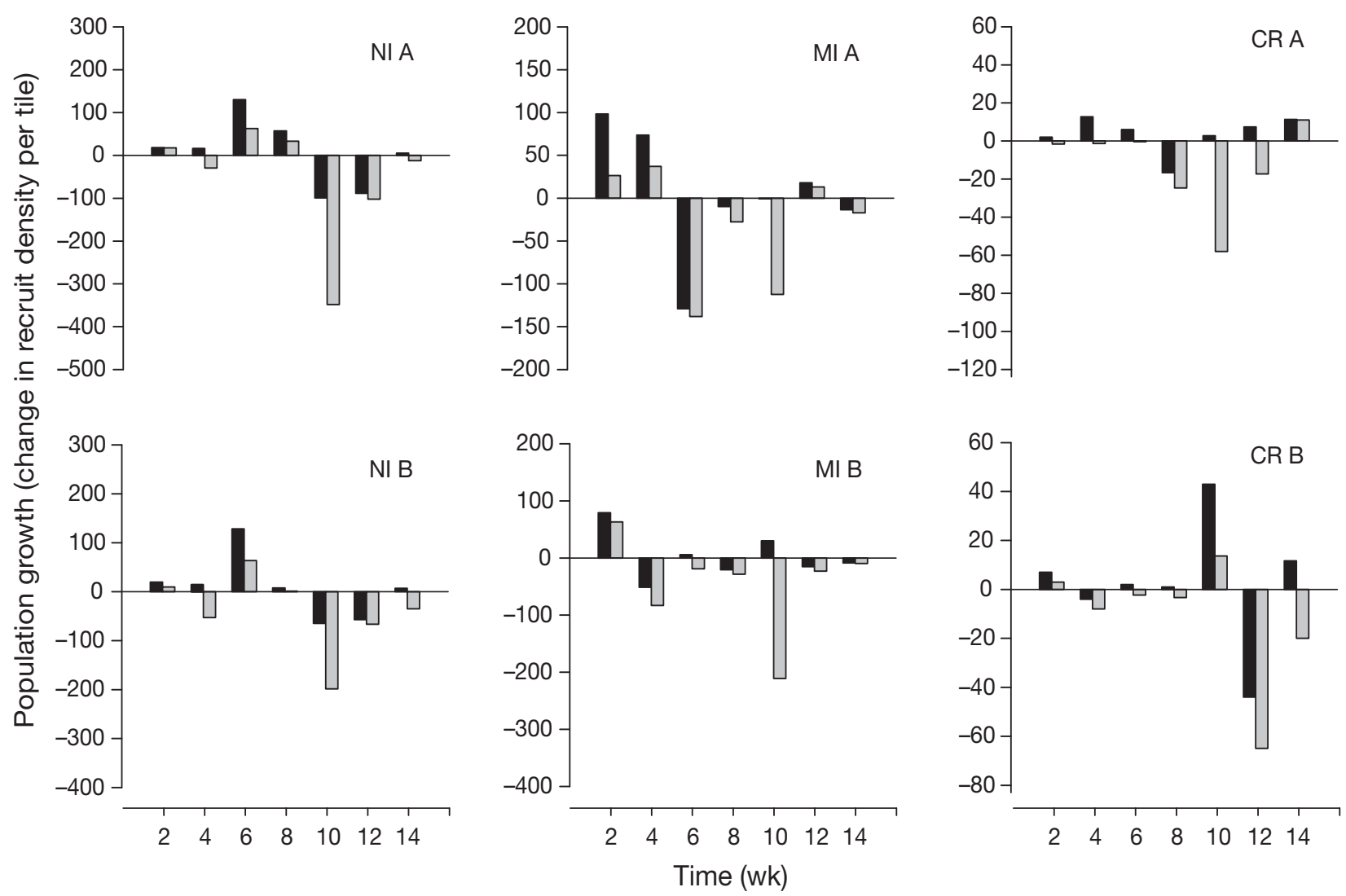

Fig. 3. Crassostrea virginica. High flow sites (Sites A and B) recruit densities in North Inlet (NI), Murrells Inlet (MI) and Cape Romain (CR). Black bars: population growth in cumulative treatments per 2 wk, calculated as the change in recruit density between Time $_{n+1}$ and Time ${ }_{n}$. Grey bars: difference between population growth in cumulative treatments per 2 wk and biweekly recruitment for that period. Positive y-values: increased recruitment or greater total recruitment; negative $y$-values: mortality, emigration and/or lower recruitment on cumulative tiles compared to biweekly tiles

In contrast, 2 peaks of increased oyster densities in low flow conditions were observed: first, the smaller of the 2 peaks between Week 4 and 6 with an average of $38 \pm 11$ and $37 \pm 10$ oysters per tile, respectively. A second, larger peak occurred between Week 8 and 10 and had an average of $59 \pm 12$ oysters per tile. Population reductions followed both peaks, with oyster numbers decreasing to similar densities with, on average, $22 \pm 6$ and $25 \pm 3$ oysters (Table 3 , SNK tests) within Week 2 and 4 . Irrespective of flow regime, the density of oysters on cumulative tiles after 14 wk were not significantly different from each other (Table 3, SNK tests).

\section{Change in cumulative recruit density in relation to biweekly recruit density}

Changes in recruitment in biweekly and cumulative treatments were tested by the null hypothesis that recruitment in each $2 \mathrm{wk}$ period, estimated by biweekly treatments, would be mirrored by cumulative treatments. That is, the change in number of individuals on cumulative tiles was predicted to increase by the same number of recruits on biweekly tiles. With the exception of peak recruitment periods, there was no difference between the number of oysters on biweekly or cumulative tiles in each 2 wk period (Table 4, Figs. 3 \& 4: grey bars). While not significantly different, in all but one case (Week 2, North Inlet, Site A, Figs. 3 $\& 4$ ) recruitment was greater on biweekly tiles than on cumulative tiles (indicated by negative values for grey bars in Figs. 3 \& 4). However, during peak recruitment periods when large influxes of biweekly recruits were recorded (e.g. Week 10 in high flow, Fig. 3), biweekly recruitment was not mirrored by cumulative tiles and in such cases, the number of recruits on cumulative tiles were significantly lower than recruitment densities estimated by biweekly treatments (Figs. 3 \& 4: grey bars, Table $4: \mathrm{p}<0.01$ ). Recruitment was significantly higher on biweekly than on cumulative tiles in Week 10 and 12 for high flow sites and in Week 8 and 12 for low flow sites (Table 4). 


\section{Density-dependent processes and population growth}

Population growth was greater at high flow locations than at low flow locations; this was likely due to the greater supply of recruits resulting in a greater probability of settlement. Changes in cumulative population

Table 4. Crassostrea virginica. Wilcoxon rank-sum test $(W)$ (Hollander \& Wolfe 1973) of difference in recruit abundance on biweekly and cumulative tiles per 2 wk period. Subscripts: sum of the rank scores on biweekly treatments. Scores are calculated by ranking recruitment numbers on both biweekly and cumulative treatments in a single row and summing the score (position value). $W_{n}$ values are compared to documented probability tables. ${ }^{*} \mathrm{p}<0.05,{ }^{* *} \mathrm{p}<0.01, \mathrm{~ns}=$ not significant

\begin{tabular}{|lll|}
\hline Time (wk) & High flow & \multicolumn{1}{c|}{ Low flow } \\
\hline 2 & $W_{10}, \mathrm{p}=0.22, \mathrm{~ns}$ & $W_{17}, \mathrm{p}=0.94, \mathrm{~ns}$ \\
4 & $W_{26}, \mathrm{p}=0.26, \mathrm{~ns}$ & $W_{17}, \mathrm{p}=0.94, \mathrm{~ns}$ \\
6 & $W_{21}, \mathrm{p}=0.68, \mathrm{~ns}$ & $W_{27}, \mathrm{p}=0.17, \mathrm{~ns}$ \\
8 & $W_{27}, \mathrm{p}=0.17, \mathrm{~ns}$ & $W_{31}, \mathrm{p}<0.05,^{*}$ \\
10 & $W_{34}, \mathrm{p}<0.01,^{* *}$ & $W_{28}, \mathrm{p}=0.10, \mathrm{~ns}$ \\
12 & $W_{31}, \mathrm{p}<0.05,{ }^{*}$ & $W_{31}, \mathrm{p}<0.05,{ }^{*}$ \\
14 & $W_{24}, \mathrm{p}=0.39, \mathrm{~ns}$ & $W_{26}, \mathrm{p}=0.23, \mathrm{~ns}$ \\
\hline
\end{tabular}

size were predictable based on biweekly recruitment estimates at high flow locations (Fig. 5a, $\mathrm{R}^{2}=0.214$ ); however, no such relationship was evident at low flow locations (Fig. 5b). Where relationships were found, comparison of linear and polynomial models showed a 2nd order polynomial model was a better fit in all cases, indicating that population growth only occurs when recruit numbers are within specific parameters. In this case, when recruitment is $>12$ and $<178$ recruits per tile, population growth occurs. When biweekly recruit densities are less than or greater than these respective values, the population declines (Fig. 5, regression model). Greatest population growth is predicted to occur when oysters recruit in densities of 103 individuals per tile. Comparison of the relationship between recruit density and cumulative change at high and low flow locations were similar at low recruit densities (<100 oysters per tile), although no predictable relationship was apparent at low flow locations and likely due to the absence of large influxes of larvae (e.g. 250 individuals per tile), thus limiting model predictions (Fig. 5b). To account for this, subsequent pooling of high and low flow data to incorporate potentially high recruitment rates at low flow locations

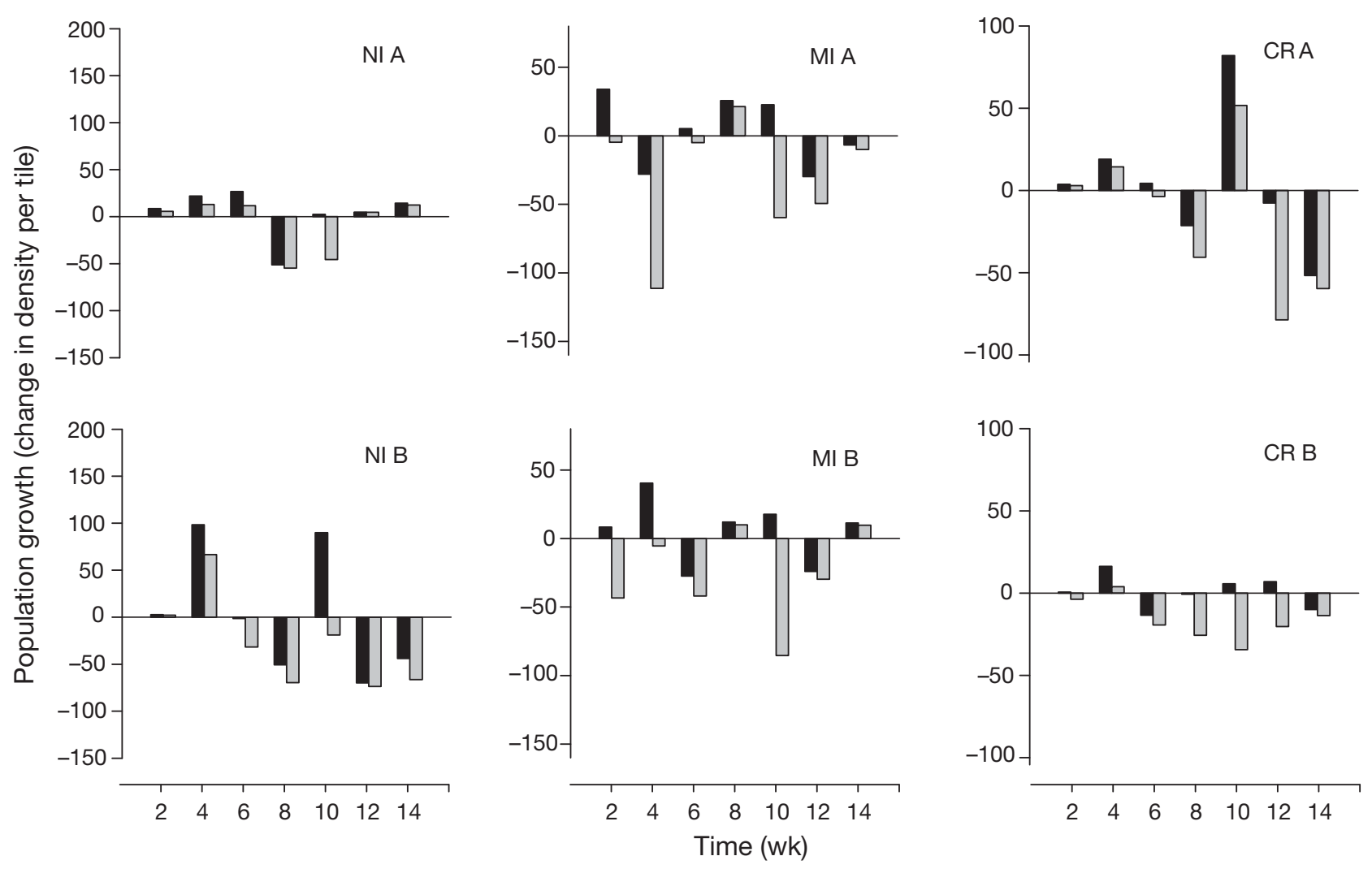

Fig. 4. Crassostrea virginica. Low flow sites (Sites A and B) recruit densities in North Inlet (NI), Murrells Inlet (MI) and Cape Romain (CR). Population growth in cumulative treatments per 2 wk (black bars) and difference between cumulative treatments and biweekly recruitment (grey bars). See Fig. 3 for more a detailed definition of black and grey bars 


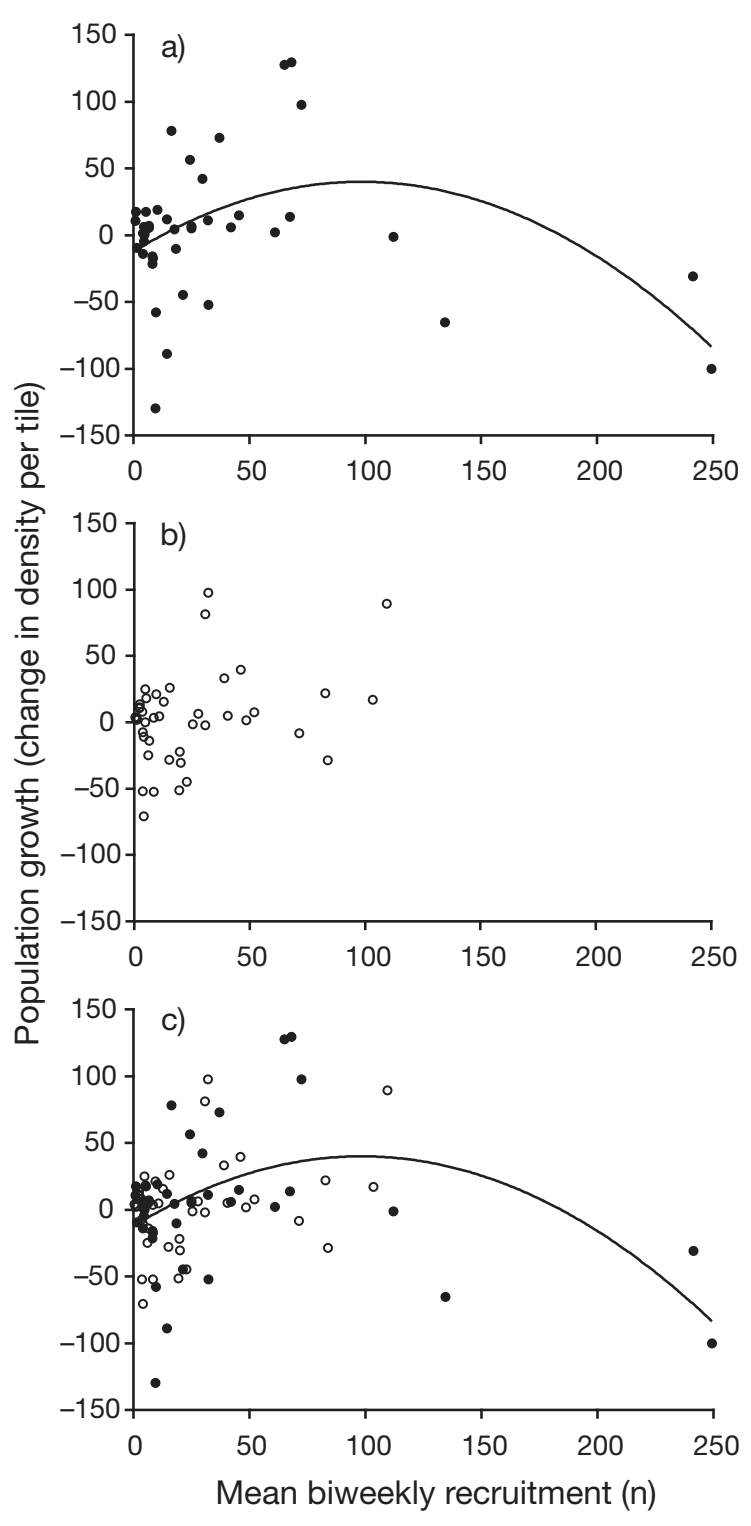

Fig. 5. Crassostrea virginica. Relationship between recruit density and population change for (a) high flow, (b) low flow, and (c) pooled high and low flow locations. Significant regression lines are (a) $y=-0.0054 x^{2}+1.0646 x-12.421, \mathrm{R}^{2}=0.214$. $F_{2,39}=5.303, \mathrm{p}<0.009$; (c) $y=-0.0048 x^{2}+0.9098 x-10.778$ $\mathrm{R}^{2}=0.172 . F_{2,81}=8.41, \mathrm{p}<0.0004$

indicated a relationship, similar to that at high flow locations, between new recruit density and population size changes (Fig. $5 c, R^{2}=0.172$ ). While significant, the relationship between biweekly recruitment and population size change accounted for a relatively low percentage $(20 \%)$ of the variation. This may be due, in part, to the large degree of variation at low levels of recruitment (i.e. $<50$ recruits), and a rapid reduction in population size and relatively few data points at higher recruitment rates.
The strength of density dependence changed in response to the density of newly arriving recruits. At low levels of recruitment, density-dependent mortality was low, indicated by comparable biweekly and cumulative treatments and reductions in population size most likely attributable to naturally high, densityindependent mortality rates for post-settlement larvae (Fig. 5). As recruit densities increase, the effect of density-dependent mortality increasingly strengthens, eventually resulting in gross reductions in existing population densities when mortality rates exceed survival rates. This was highlighted by far fewer recruits in cumulative treatments than in biweekly treatments (indicated by negative values, Fig. 5). However, the exact role of density dependence in the decline of Crassostrea virginica populations was unclear. When recruit influx was at its greatest, the immediate effect on the existing population was unpredictable and contradictory depending on the flow regime. At high flow locations, populations declined on average $15 \%$ from the previous estimates, whereas at low flow locations, populations continued to grow by $50 \%$ (Figs. 2 to 5 ; Table 3, Flow). Recruits were, however, twice as prevalent at high flow locations than at low flow locations (Figs. 2 to 5, Table 3) and may have resulted in differences in the strength of density dependence between previously settled and newly arriving recruits. Irrespective of differences in recruit densities among flow regimes, a time-lag was apparent whereby the following 2 to 4 wk period post peak recruitment coincided with marked reductions in population size and oyster densities were reduced between 34 and $50 \%$ (Figs. 3 \& 4, Table 3, Time, SNK tests). This pattern was evident at all sites within each of the locations.

\section{DISCUSSION}

With variable population size and structure coupled with unequal larval connectivity between populations (Hanski \& Simberloff 1997), population development predictions are likely to be locally specific with many biotic and abiotic factors affecting distributional patterns (Kingsford 1993). However, the timing and pattern of recruitment in the present study was consistent with previous studies and characterised by 2 distinct peak settlement periods: first in early June and subsequently in early to mid-July (e.g. Loosanoff \& Nomejko 1956, Haven \& Fritz 1985, Kenny et al. 1990, Michener \& Kenny 1991). Great variability in recruit densities at both the smallest (tile) and larger (site) spatial scales was found and likely due to fluctuations in water quality, predation, food availability, water temperature and other factors that affect settlement success (Abbe 1986, Kennedy 1986). 
Recruitment was used as a proxy for settlement, with settlers defined as the number of individuals remaining on each tile after a short time period (2 wk). Biweekly tiles were used to estimate the total settlement for each 2 wk time period and compared to changes in population size (recruits) on cumulative tiles over the same $2 \mathrm{wk}$ period, with the result that recruitment onto either type of tile was similar in all periods, suggesting that changes in population size occur post-recruitment. Our study did not attempt to manipulate recruit and adult densities directly; rather, the goal was to identify patterns based on local and regional patterns of recruitment and to assess their potential effect on existing recruit populations. There was a clear and spatially consistent relationship between the density of newly arriving recruits and abundance of oysters on each tile at the regional level over the $14 \mathrm{wk}$ period. During peak recruitment, the interaction between the aging population and newly arriving recruits was markedly different to periods of low and intermediate recruitment. The strong positive relationship between biweekly recruits and population growth at low and intermediate recruitment rates became a strongly negative relationship, in which the populations exhibited marked reductions in size at greatest recruit densities. Notably, while the relationship between population size and recruit density at low and intermediate rates was positive, the population declined at extremely low recruitment rates, indicating that a minimum number of recruits are required if a population is to persist. A hump-shaped relationship between recruit and adult densities has been demonstrated in several theoretical studies (see Murdoch 1994 for review) where populations are determined by a combination of both density-independent (low recruitment) and density-dependent (high recruitment) mortality (e.g. Connell 1985, Caley et al. 1996), but until recently, this relationship has rarely been demonstrated in open marine populations (but see Jenkins et al. 2008).

Large reductions in adult densities occurred in conjunction with periods of peak recruitment and are well documented for many species with variable recruitment patterns, e.g. Californian sardine Sardinops caerulea and Peruvian anchoveta Engraulis ringens (Iles \& Beverton 2000). The rapid aggregation and growth of conspecifics can induce density-dependent mortality through intraspecific competition (e.g. Shima 2001, Wilson \& Osenberg 2002) with the result that the local population size adjusts to a specific carrying capacity over time (Iles \& Beverton 2000). Comparable densities of Crassostrea sp. among locations after 14 wk indicate recruitment follows the recruitmentlimitation hypothesis (sensu Doherty \& Williams 1988). Reductions generally occurred within a 2 to 4 wk period, suggesting a time-lag between recruitment and population contraction. The fact that there were similar oyster densities after $14 \mathrm{wk}$ indicates a consistent and predictable regional carrying capacity for South Carolinian oyster populations. It does not, however, explain why reductions occurred after peak recruitment and not earlier, when recruit densities exceed this level. A potential explanation for a timelag would be that newly settled larvae are able to survive on protein reserves for a limited time prior to being able to successfully compete for resources (Garcia-Esquivel et al. 2001), but are subsequently restricted by resource availability. The rate of densitydependent mortality increased in conjunction with recruit density increases. Relationships were derived from examination of a range of recruit densities and this approach perhaps provides a more realistic assessment of density-dependence than previous studies, which focused solely on a presence/absence approach (e.g. Connell 1985, Caley et al. 1996). A limitation of this approach, however, is that it examines a continual additive process where recruits continue to arrive over time. As a result, there may be some disparity in age/size among recruits dependent on the time (wk) of recruitment, which may not only alter the surrounding physical environment, e.g. increased sediment accumulation or increased substrate in the form of shells, but also effect the intraspecific interaction among recruits through processes such as conspecific attraction (e.g. Tamburri et al. 2007), ultimately affecting rates of recruitment among treatments. Thus, while allowing predictions of the apparent change in population size in relation to absolute recruitment, the additive approach may mask the precise role of recruitment pulses in density-dependent processes and its role in population regulation when the carrying capacity is exceeded.

The density of recruits was greater at high flow locations than at low flow locations. Different flow regimes are known to greatly affect the dispersal and settlement of larvae. Increased water velocities may facilitate settlement by passing a greater volume of water over the substrate per unit time. The probability of larvae coming into contact with an area of available substrate is therefore enhanced (e.g. Crimaldi et al. 2002), especially when considering the limited swimming speeds of pelagic larvae (Mann \& Rainer 1990). Recent studies have indicated that several marine species have an inherent ability to manipulate or control their vertical position within the water column in order to facilitate transport in flow velocities which are orders of magnitude greater than their own swimming velocity (e.g. Pernet et al. 2003, Knights et al. 2006). Settlement may also occur in response to chemical cues of habitat suitability (Pawlik 1992) exuded by conspecific 
adults - gregarious settlement being an indicator of favourable conditions in both the barnacle Chamaesipho tasmanica (Jeffery 2000) and oyster Crassostrea gigas (Tamburri et al. 2007). Such behavioural changes by oyster larvae in response to chemical cues (Crassostrea spp., Turner et al. 1994, Tamburri et al. 2007) are proposed to increase the likelihood of suitable substrate contact and, thus, settlement. Such mechanisms, either singularly or in combination, may underlie the patterns documented in the present study.

Measurement of recruitment can potentially confound the role of larval settlement in population dynamics when density-dependent, early post-settlement mortality occurs (Jenkins et al. 2008). Like many marine species that undergo a pelagic-demersal metamorphosis, Crassostrea spp. experience high rates of early post-settlement mortality (Haws et al. 1993, Garcia-Esquivel et al. 2000). Previous studies suggest that early post-settlement mortality is predominantly density independent and, thus, recruitment a direct approximation of settlement (e.g. Connell 1985, Holm 1990, Roegner \& Mann 1995, Caley et al. 1996). Postsettlement mortality may be attributed to several factors, e.g. desiccation, temperature stress, mechanical damage and predation (Gosselin \& Qian 1997), and may exceed $98 \%$ for many marine benthic invertebrates (Thorson 1966). Factors such as these may account for a significant proportion of the additional variation not described by the population change model in our study (Fig. 4). Great care was taken to select similar environments to ensure that the density and size distribution of adult Crassostrea virginica were similar among locations so that initial post-spawning larval densities within the water column were more likely to be comparable. Larval density may, however, become decoupled from adult population densities over the typical 2 to 3 wk planktonic duration, with other factors such as local hydrodynamics potentially affecting the supply of larvae to those habitats. Future studies should include estimates of larval densities within the water column in an attempt to couple larval flux and the resultant recruitment rates. Shore height, tidal inundation and predator identity and density were also compared at the start of the study to ensure similar environmental conditions among locations. The scope of this study did not include potential factors, such as space limitation with increasing population size (Jeffery 2000), food availability (Abbe 1986) or larval behaviour in response to settlement cues (Raimondi 1988, Crimaldi et al. 2002, Pernet et al. 2003). However, equal substrate availability among treatments, the apparent available that space on each tile at collection (A. M. Knights unpubl. data) and proximity to large expanses of adult $C$. virginica suggest that space and food are not limiting factors in this case.
This study demonstrates the role of recruitment in the maintenance and development of adult populations. Recruitment clearly plays an important role in population persistence when insufficient supply of recruits coupled with high density-independent mortality results in population decline or extinction, and high rates of recruitment lead to increasing rates of density-dependent mortality. Higher water flow velocities increased recruitment in the short-term. Greater recruitment, however, increased the densitydependent mortality of existing recruits, resulting in populations of a similar size, irrespective of rates of recruitment. Population size is, therefore, most likely determined by a combination of resource availability which determines the size of population that may be supported, and sufficient recruitment to overcome high mortality rates. This study adopted a multi-factorial approach using a range of recruit densities to assess the role of recruitment relative to other potentially limiting and regulatory processes that determine population size. A common goal of population management is to identify and protect key stages in the life history of the study organism that maintain or enhance the survival of existing populations. Studies that explicitly examine the role of density-dependence in population persistence at the recruitment level may enhance our understanding of the structure and development of benthic invertebrate populations. Future work should aim to determine the effect of adult population density on recruitment success and habitat selection processes.

Acknowledgements. This study was funded by a grant from the National Fish and Wildlife Foundation through the Savannah-Santee-Pee Dee Resource Protection Fund to K.W. Thanks to P. Kenny (USC Baruch Marine Lab), B. Chandler (Murrells Inlet) and US Fish and Wildlife Service (Cape Romain) for access to field sites. L. Firth, R. Hillard, Savannah-Santee-Pee Dee Resource Protection Fund, L. Coen and students in CCUs Advanced Population Biology of Marine Organisms class made significant contributions to field and laboratory work. L. Firth and L. Coen made many useful comments to help improve this manuscript. Thank you also to the 3 anonymous reviewers who helped to improve this manuscript.

\section{LITERATURE CITED}

Abbe GR (1986) A review of some factors that limit oyster recruitment in Chesapeake Bay. Am Malacol Bull 3:59-70

Armonies W, Hellwigarmonies M (1992) Passive settlement of Macoma balthica spat on tidal flats of the Wadden Sea and subsequent migration of juveniles. Neth J Sea Res 29: 371-378

Begon M, Harper JL, Townsend CR (1990) Individuals, populations and communities. Blackwell Scientific Publishing, Boston, MA

Bouma H, Duiker JMC, de Vries PP, Herman PMJ, Wolff WJ 
(2001) Spatial pattern of early recruitment of Malcoma balthica (L.) and Cerastoderma edule (L.) in relation to sediment dynamics on a highly dynamic intertidal sandflat. J Sea Res 45:79-93

Breitburg DL (1999) Are three-dimensional structure and healthy oyster populations the keys to an ecologically interesting and important fish community? In: Luckenbach MW, Mann R, Wesson JA (eds) Oyster reef habitat restoration: a synopsis and synthesis of approaches. Virginia Institute of Marine Science Press, Gloucester Point, VA, p 239-249

Burke RD (1986) Pheromones and the gregarious settlement of marine invertebrate larvae. Bull Mar Sci 39:323-331

Byrnes JE, Reynolds PL, Stachowicz JJ (2007) Invasions and extinctions reshape coastal marine food webs. PloS ONE 2(3):e295, doi:10.1371/journal.pone.0000295

Caley MJ, Carr MH, Hixon MA, Hughes TP, Jones GP, Menge BA (1996) Recruitment and the local dynamics of open marine populations. Annu Rev Ecol Syst 27:477-500

Coen LD, Luckenbach MW, Breitburg DL (1999) The role of oyster reefs as essential fish habitat: a review of current knowledge and some new perspectives. Am Fish Soc Symp 22:438-454

Connell JH (1985) The consequences of variation in initial settlement vs. post-settlement mortality in rocky intertidal communities. J Exp Mar Biol Ecol 93:11-43

Crimaldi J, Thompson J, Rosman J, Lowe R, Koseff J (2002) Hydrodynamics of larval settlement: the influence of turbulent stress events at potential recruitment sites. Limnol Oceanogr 47:1137-1151

Crisp DJ, Meadows PS (1962) The chemical basis of gregariousness in cirripedes. Proc R Soc Lond B Biol Sci 156: 500-520

Day RW, Quinn GP (1989) Comparisons of treatments after an analysis of variance in ecology. Ecol Monogr 59:433-463

den Boer PJ (1981) On the survival of populations in a heterogeneous and variable environment. Oecologia 50:39-53

Doherty P, Williams DM (1988) The replenishment of coral reef populations. Oceanogr Mar Biol Annu Rev 26: 487-551

Garcia-Esquivel Z, Gonzalez-Gomez MA, Gomez-Togo DL, Galindo-Bect MS, Hernandez-Ayon M (2000) Microgeographic differences in growth, mortality, and biochemical composition of cultured Pacific oysters (Crassostrea gigas) from San Quintin Bay, Mexico. J Shellfish Res 19:789-797

> Garcia-Esquivel Z, Bricelj VM, Gonzalez-Gomez MA (2001) Physiological basis for energy demands and early postlarval mortality in the Pacific oyster, Crassostrea gigas. J Exp Mar Biol Ecol 263:77-103

Gosselin LA, Qian PY (1997) Juvenile mortality in benthic marine invertebrates. Mar Ecol Prog Ser 146:265-282

Gotelli NJ (2001) A primer of ecology. Sinauer Associates, Sunderland, MA

Hanski I, Simberloff D (1997) The metapopulation approach, its history, conceptual domain, and application to conservation. In: Hanski I, Gilpin M (eds) Metapopulation biology: ecology, genetics and evolution. Academic Press, San Diego, CA, p 5-26

Haven DS, Fritz LW (1985) Setting of the American oyster Crassostrea virginica in the James River, Virginia, USA: temporal and spatial distribution. Mar Biol 86:271-282

Haws MC, DiMichele L, Hand SC (1993) Biochemical changes and mortality during metamorphosis of the eastern oyster, Crassostrea virginica, and the Pacific oyster, Crassostrea gigas. Mol Mar Biol Biotechnol 2:207-217

Hollander M, Wolfe DA (1973) Nonparametric statistical methods. John Wiley \& Sons, New York
Holm ER (1990) Effects of density-dependent mortality on the relationship between recruitment and larval settlement. Mar Ecol Prog Ser 60:141-146

> Iles TC, Beverton RJH (2000) The concentration hypothesis: the statistical evidence. ICES J Mar Sci 57:216-227

Jeffery CJ (2000) Settlement in different-sized patches by the gregarious intertidal barnacle Chamaesipho tasmanica Foster and Anderson in New South Wales. J Exp Mar Biol Ecol 252:15-26

Jenkins SR, Murua J, Burrows MT (2008) Temporal changes in the strength of density-dependent mortality and growth in intertidal barnacles. J Anim Ecol 77:573-584

> Jones CG, Lawton JH, Shachak M (1994) Organisms as ecosystem engineers. Oikos 69:373-386

Judge ML, Craig SF (1997) Positive flow dependence in the initial colonization of a fouling community: results from in situ water current manipulations. J Exp Mar Biol Ecol 210: 209-222

Kennedy VS (1986) Expected seasonal presence of Crassostrea virginica (Gmelin) larval populations, emphasizing Chesapeake Bay. Am Malacol Bull 3:25-29

Kenny PD, Michener WK, Allen DM (1990) Spatial and temporal patterns of oyster settlement in a high salinity estuary. J Shellfish Res 9:329-339

Kingsford MJ (1993) Biotic and abiotic structure in the pelagic environment: importance to small fishes. Bull Mar Sci 53: 393-415

Knights AM, Crowe TP, Burnell GM (2006) Mechanisms of larval transport: vertical distribution of bivalve larvae varies with tidal conditions. Mar Ecol Prog Ser 326: $167-174$

Kritzer JP, Sale PF (2004) Metapopulation ecology in the sea: from Levins' model to marine ecology and fisheries science. Fish Fish 5:131-140

Lenihan HS (1999) Physical-biological coupling on oyster reefs: how habitat form influences individual performance. Ecol Monogr 69:251-275

Leonard GH, Levine JM, Schmidt PR, Bertness MD (1998) Flow-driven variation in intertidal community structure in a Maine estuary. Ecology 79:1395-1411

> Loosanoff VL, Nomejko CA (1956) Relative intensity of oyster setting in different years in the same areas of Long Island Sound. Biol Bull 111:387-392

Mann R, Rainer JS (1990) Effect of decreasing oxygen tension on swimming rate of Crassostrea virginica Gmelin 1791 larvae. J Shellfish Res 9:323-328

> McQuaid CD, Phillips TE (2000) Limited wind-driven dispersal of intertidal mussel larvae: in situ evidence from the plankton and the spread of the invasive species Mytilus galloprovincialis in South Africa. Mar Ecol Prog Ser 201: 211-220

Michener WK, Kenny PD (1991) Spatial and temporal patterns of Crassostrea virginica (Gmelin) recruitment: relationship to scale and substratum. J Exp Mar Biol Ecol 154: 97-121

> Murdoch W (1994) Population regulation in theory and practice. Ecology 75:271-287

Murdoch WW, McCauley E (1985) Three distinct types of dynamic behaviour shown by a single planktonic system. Nature 316:628-630

Newell RIE (2004) Ecosystem influences of natural and cultivated population of suspension-feeding bivalve molluscs: a review. J Shellfish Res 23:51-61

Pawlik JR (1992) Chemical ecology of the settlement of benthic marine invertebrates. Oceanogr Mar Biol Annu Rev 30:273-335

Pernet F, Tremblay R, Bourget E (2003) Settlement success, 
spatial pattern and behavior of mussel larvae Mytilus spp. in experimental 'downwelling' systems of varying velocity and turbulence. Mar Ecol Prog Ser 260:125-140

Pimm SL, Jones HL, Diamond JM (1988) On the risk of extinction. Am Nat 132:757-785

Porter ET, Sanford LP, Suttles SE (2000) Gypsum dissolution is not a universal integrator of 'water motion'. Limnol Oceanogr 45:145-158

Raimondi PT (1988) Settlement cues and determination of the vertical limit of the intertidal barnacle. Ecology 69: 400-407

Regan HM, Lupia R, Drinnan AN, Burgman MA (2001) The currency and tempo of extinction. Am Nat 157:1-10

Roegner GC (2000) Transport of molluscan larvae through a shallow estuary. J Plankton Res 22:1779-1800

$>$ Roegner GC, Mann R (1995) Early recruitment and growth of the American oyster Crassostrea virginica (Bivalvia, Ostreidae) with respect to tidal zonation and season. Mar Ecol Prog Ser 117:91-101

Shima JS (2001) Regulation of local populations of a coral reef fish via joint effects of density- and number-dependent mortality. Oecologia 126:58-65

Sokal RR, Rohlf FJ (1995) Biometry. W.H. Freeman, New York, NY

Tamburri MN, Zimmer RK, Zimmer CA (2007) Mechanisms reconciling gregarious larval settlement with adult cannibalism. Ecol Monogr 77:255-268

Thompson TL, Glenn EP (1994) Plaster standards to measure water motion. Limnol Oceanogr 39:1768-1779

Thorson G (1950) Reproductive and larval ecology of marine bottom invertebrates. Biol Rev Camb Philos Soc 25:1-45

Editorial responsibility: Richard Osman,

Edgewater, Maryland, USA
Thorson G (1966) Some factors influencing the recruitment and establishment of benthic marine communities. Neth J Sea Res 3:267-293

Turner EJ, Zimmer-Faust RK, Palmer MA, Luckenback M (1994) Settlement of oyster (Crassostrea virginica) larvae: effects of water flow and a water-soluble chemical cue. Limnol Oceanogr 39:1579-1593

Underwood AJ (1997) Experiments in ecology: their logical design and interpretation using analysis of variance. Cambridge University Press, Cambridge

Underwood AJ, Chapman MG (1998) General model analysis of variance 5. Institute of Marine Ecology, University of Sydney, Sydney

Underwood AJ, Keough MJ (2001) Supply-side ecology: the nature and consequences of variations in recruitment of intertidal organisms. In: Bertness MD, Gaines MS, Hay M (eds) Marine community ecology. Sinauer Associates, Sunderland, MA, p 183-200

Walters K, Coen LD (2006) A comparison of statistical approaches to analyzing community convergence between natural and constructed oyster reefs. J Exp Mar Biol Ecol 330:81-95

Wilson JB, Osenberg CW (2002) Experimental and observational patterns of density-dependent settlement and survival in the marine fish Gobiosoma. Oecologia 130: 205-215

Woodin SA (1976) Adult-larval interactions in dense infaunal assemblages: patterns of abundance. J Mar Res 34: 25-41

Yund PO, Gaines SD, Bertness MD (1991) Cylindrical tube traps for larval sampling. Limnol Oceanogr 36:1167-1177

Submitted: January 27, 2009; Accepted: January 6, 2010

Proofs received from author(s): March 28, 2010 